Dear author,

Please note that changes made in the online proofing system will be added to the article before publication but are not reflected in this PDF.

We also ask that this file not be used for submitting corrections. 


\title{
Q1 A study on the corrosion of reinforcing bars in alkali-activated fly ash mortars under wet and dry exposures to chloride solutions
}

\author{
Q2 C. Monticelli a,*, M.E. Natali ${ }^{\text {b }}$, A. Balbo ${ }^{\text {c }}$, C. Chiavari ${ }^{\text {d,e }}$, F. Zanotto ${ }^{\text {f }}$, S. Manzi ${ }^{\text {g }}$, M.C. Bignozzi ${ }^{\text {h }}$ \\ a Centro di Studi sulla Corrosione e Metallurgia “A. Daccò”, Università di Ferrara, Via Saragat 4a, 44122 Ferrara, Italy \\ b Dipartimento di Ingegneria Civile, Chimica, Ambientale e dei Materiali, Università di Bologna, Via Terracini 28, 40131 Bologna, Italy \\ c Centro di Studi sulla Corrosione e Metallurgia “A. Daccò”, Università di Ferrara, Via Saragat 4a, 44122 Ferrara, Italy \\ Q3 d C.I.R.I. (Centro Interdipartimentale Ricerca Industriale) Meccanica Avanzata e Materiali, Università di Bologna, Bologna, Via Terracini 28, 40131 Bologna, Italy \\ e Dipartimento di Beni Culturali, Università di Bologna, Via degli Ariani, 1, 48121 Ravenna, Italy \\ ${ }^{\mathrm{f}}$ Terra\&Acqua Tech, Università di Ferrara, Via Saragat 4a, 44122 Ferrara, Italy \\ g Dipartimento di Ingegneria Civile, Chimica, Ambientale e dei Materiali, Università di Bologna, Via Terracini 28, 40131 Bologna, Italy \\ h Dipartimento di Ingegneria Civile, Chimica, Ambientale e dei Materiali, Università di Bologna, Via Terracini 28, 40131 Bologna, Italy
}

\section{A R T I C L E I N F O}

\section{Article history:}

Received 6 February 2016

Received in revised form 24 May 2016

Accepted 27 May 2016

Available online $\mathrm{xxxx}$

\section{Keywords:}

D. Alkali activated cement

C. Corrosion

D. Chloride

C. Mechanical properties

B. Microstructure

\begin{abstract}
A B S T R A C T
This research investigates the corrosion protection afforded to the embedded rebars by room temperature-cured 24 alkali-activated mortars, based on class F fly ash (FA), during wet and dry (w/d) exposures to $0.1 \mathrm{M} \mathrm{NaCl}$ solution. 25 The results were compared to those obtained in a traditional cement-based mortar (REF). The rebar corrosion be- 26 haviour was characterized by corrosion potentials $\left(\mathrm{E}_{\mathrm{cor}}\right)$ and potentiostatic polarization resistance $\left(\mathrm{R}_{\mathrm{p}}\right)$ measure- 27 ments, polarization curve recording and electrochemical impedance spectroscopy (EIS). The information 28 collected suggested that FA mortars afforded a lower corrosion protection to the rebars and the reason was inves- 29 tigated by microstructural, physical-mechanical and chemical analyses of the mortars. FA mortars were found to 30 undergo a fast carbonation, so that depassivation of the rebars occurred concurrently, in spite of a limited total 31 chloride content inside these mortars. REF mortar was much less susceptible to carbonation and rebar corrosion 32 started when a sufficiently high chloride concentration was built up.
\end{abstract}

(C) 2015 Published by Elsevier Ltd. 34

\section{Introduction}

The increasing focus on issues concerning environmental sustainability and the enhancement of recycled materials and industrial wastes is stimulating research into the development of alternative sustainable building materials. With regard to traditional construction materials, the environmental impact of ordinary Portland cement (OPC), which produces nearly one ton of $\mathrm{CO}_{2}$ per ton of cement, is well-known. $50 \%$ of its carbon dioxide emissions are caused by the processing of raw materials, $40 \%$ by the fuel consumption required to achieve the high processing temperatures $\left(1450{ }^{\circ} \mathrm{C}\right)$ and the remaining $10 \%$ by the use of electricity and transportation [1]. Similar considerations may also apply to traditional ceramic materials (bricks and tiles), for which natural origin raw materials and high processing temperatures are used (between 1000 and $1300^{\circ} \mathrm{C}$ ).

\footnotetext{
* Corresponding author.

E-mail addresses: mtc@unife.it (C. Monticelli),mariaelia.natali2@unibo.it (M.E. Natali), andrea.balbo@unife.it (A. Balbo), cristina.chiavari@unibo.it (C. Chiavari), federica.zanotto@unife.it (F. Zanotto),stefania.manzi4@unibo.it (S. Manzi), maria.bignozzi@unibo.it (M.C. Bignozzi).
}

Alkali-activated materials (AAMs), which include geopolymers as 59 the subset with the higher amount of silica and alumina and the lowest 60 content of calcium oxide, represent a viable alternative to traditional 61 building materials $[2,3]$. The alkali activation is a chemical process, 62 which induces dissolution/reprecipitation reactions on amorphous 63 alumino-silicate powders giving origins to solid products quite similar 64 to cement paste or ceramics. The consolidation process takes place at 65 moderate temperatures $\left(20 \leq \mathrm{T} \leq 100^{\circ} \mathrm{C}\right)$ and, thanks to their specific 66 chemical compositions, it is possible to activate various types of indus- 67 trial wastes such as ground-granulated blast furnace slag (GGBS), 68 coal-derived fly ash (FA) and other types of precursors derived from 69 waste streams such as coal gangue and red mud [4]. These kinds of 70 wastes are today only partially used, and without large opportunities 71 for recycling, so that they are commonly disposed in landfills. The sus- 72 tainability advantage of the alkali activation process is thus evident, as 73 it allows the realization of materials that can be used as alternatives to 74 OPC pastes or ceramics, with the same forming techniques (casting, ex- 75 trusion, etc.) and final performances.

In view of exploiting the potentialities of AAMs as construction ma- 77 terials, the scientific community is now concentrated in understanding 78 and optimizing the geopolymerization process and much work is 79 focused on achieving high material durability [5-7]. Concerning 80 
reinforced structures, it is very important to understand if alkaliactivated binders can guarantee the steel reinforcements a protectiveness comparable to that offered by OPC, also in aggressive environments. In fact, corrosion of reinforced elements is one of the main causes of structural failures, generally connected to carbonation and/ or chloride penetration [8].

The corrosion behaviour of steel rebars in activated fly ash mortars depends on many factors, which still need to be fully investigated. Among these factors, the composition and nature of alkaline activator, the mortar/concrete curing temperature and the exposure conditions play a fundamental role. As far as the activating solution composition is concerned, it was found that the addition of sodium silicate to sodium hydroxide stimulated network formation in geopolymers so leading to improved mechanical strength, lowering chloride ion mobility and slightly improving corrosion performances [9-11]. However, also a high sodium hydroxide content was observed to improve the geopolymer protective properties because of stimulation of the geopolymerization rate [12]. The addition of an alkaline solid activator based on sodium silicate and sodium carbonate induced a descending alkaline $\mathrm{pH}$ in mortar specimens and/or a high total porosity [13]. In geopolymers, the presence of high concentrations of inhibiting silicate ions in the pore electrolyte was reputed to contribute to reinforce steel passivity [14,15]. The durability of reinforced geopolymer specimens in high relative humidity atmosphere was proved to be quite high and comparable to that in traditional mortars, in the absence of admixed chlorides or in the presence of a limited chloride contamination. Instead, the addition of $2 \%$ chlorides to the mortar mixes impaired the stability of the rebar passive films $[10,13,16]$. During continuous contact with $3.5 \%$ $\mathrm{NaCl}$ solution [10] or wet and dry (w/d) exposure to this solution [12], the performances of reinforced geopolymer specimens were slightly better than those in OPC-based reference specimens. The latter alternated immersion tests were carried out on high temperature-cured geopolymer specimens to improve the concrete performances. Actually, high temperature curing is a quite common way to achieve high geopolymer durability $[9,12,13,16,17]$, although this reduces the material environmental sustainability and its use on building sites. Thus, many efforts aim at formulating room temperature (RT) activation of these new construction materials [18-21].

The aim of this paper was to evaluate the performances of reinforced RT-cured geopolymer mortars subjected to w/d cycles in chloride solution. Three different mortar compositions were formulated by modifying the $\mathrm{Na}_{2} \mathrm{O} / \mathrm{SiO}_{2}$ ratio and their performances were compared to those of a traditional cement-based mortar. The corrosion behaviour of the embedded rebars was investigated by electrochemical tests (potentiostatic polarization resistance $\left(\mathrm{R}_{\mathrm{p}}\right)$ measurements, electrochemical impedance spectroscopy (EIS) and polarization curve recording) and by a concomitant physical-chemical investigation of the mortar microstructures and characteristics, which helped interpretation of electrochemical test results.

\section{Materials and methods}

\subsection{Raw materials}

Geopolymers were prepared using class F FA sourced from the Enel Produzione S.p.A Italian power station of Torrevaldaliga, Civitavecchia, Roma and supplied by General Admixtures S.p.A. (Ponzano Veneto, Treviso, Italy). It is a fine $\left(\mathrm{d}_{50}=22 \mu \mathrm{m}\right)$ and mostly amorphous FA (65 \pm 0.8 wt.\%) with chemical composition, expressed in main oxide content, as follows: $\mathrm{SiO}_{2}=49.0, \mathrm{Al}_{2} \mathrm{O}_{3}=29.2, \mathrm{Fe}_{2} \mathrm{O}_{3}=2.7, \mathrm{CaO}=$ $6.6, \mathrm{MgO}=1.1, \mathrm{SO}_{3}=0.3, \mathrm{Na}_{2} \mathrm{O}<0.05, \mathrm{~K}_{2} \mathrm{O}=0.6 \mathrm{wt} . \%$. A detailed characterization of this FA is reported elsewhere [20].

The chosen activator solutions for the studied systems consisted in different mixtures of sodium silicate solution $\left(\mathrm{SiO}_{2} / \mathrm{Na}_{2} \mathrm{O}=1.99\right.$ as molar ratio, density at $20{ }^{\circ} \mathrm{C}=1.5 \pm 0.2 \mathrm{~g} / \mathrm{cm}^{3}$, Ingessil, Verona, Italy) and $8 \mathrm{M} \mathrm{NaOH}$ solution, which were pre-mixed $24 \mathrm{~h}$ before sample 144 preparation and additionally stirred immediately before casting. $\quad 145$

CEM II/A-LL 42.5 R was used as reference binder while natural sand 146 with standardized grain size distribution according to EN 196-1 [22] 147 was used as aggregate for FA and cement-based mortar samples.

\subsection{Mortar design and characterization}

The samples were prepared by keeping constant both the binder 150 amount (FA or cement) and the binder/sand and liquid/binder (L/B) ra- 151 tios (binder/sand $=1: 2.7$ and $\mathrm{L} / \mathrm{B}=0.52$ ). For geopolymers, the liquid 152 part consisted in a fixed amount of alkaline solutions (10.7 wt.\%) plus 153 water (1.6 wt.\%). Three different mixes of geopolymers were prepared 154 by changing the relative amounts of $8 \mathrm{M} \mathrm{NaOH}$ and sodium silicate so- 155 lutions in order to achieve specific molar ratios of $\mathrm{Na}_{2} \mathrm{O} / \mathrm{SiO}_{2}$, namely 156 equal to $0.12,0.14$ and 0.16 (chosen on the basis of previous works 157 $[10,20])$. Geopolymer mortars were referred to as G_1, G_2 and G_3 158 $\left(\mathrm{Na}_{2} \mathrm{O} / \mathrm{SiO}_{2}=0.12,0.14\right.$ and 0.16 , respectively), while cement mortar 159 samples were named REF.

Before casting, the mortar consistency was determined in the fresh 161 state by flow-table test. All the slurries exhibited a good consistency 162 showing an average spread diameter of about $200 \mathrm{~mm}$. Geopolymer 163 slurries were denser compared to REF and, among the FA-based formu- 164 lations, G_3 exhibited the fastest setting time (20 min compared to 165 $40 \mathrm{~min}$, as average) thus meaning that the presence of a higher content 166 of $\mathrm{NaOH}$ accelerates consolidation reactions.

167

The slurries were cast in different types of moulds (cylinders, prisms 168 or cubes), depending on the characterization tests.

Sixteen cylinders $(\mathrm{h}=100 \mathrm{~mm}, \varphi=35 \mathrm{~mm}$ ) were cast for each type 170 of mortar. Ten cylinders were prepared for electrochemical tests with 171 embedded rebars (acting as working electrodes, W) and activated tita- 172 nium wires (acting as quasi-reference low-impedance electrodes (R)), 173 which were fixed in the proximity of each reinforcement (Fig. 1a). 174

The rebars were ribbed carbon steel rods (sandblasted surface, 175 $\varphi=10 \mathrm{~mm}$ ) with both ends masked by epoxy paint. This surface 176 protection was made more long-lasting by applying a further ther- 177 moset band on the paint. The area of the exposed surface was 178 $1000 \mathrm{~mm}^{2}$. These rebars were positioned along the longitudinal 179 axis of the cylindrical samples, so that the mortar cover was about 180 $13 \mathrm{~mm}$.

Further six unreinforced cylinders were prepared for chloride con- 182 tent and $\mathrm{pH}$ measurements (Fig. 1b).

Prismatic samples $\left(40 \times 40 \times 160 \mathrm{~mm}^{3}\right)$ and cubes 184 $\left(100 \times 100 \times 100 \mathrm{~mm}^{3}\right)$ were also cast, for mechanical and micro- 185 structural characterization and chloride diffusion test, respectively. 186

Both geopolymer and REF mortar samples were vibrated on a shaker 187 table to reduce entrained air and cured for 28 days under conditions 188 chosen with the aim to maximize their mechanical properties. In partic- 189 ular, independently from the absence or presence of a reinforcing bar, 190 geopolymers were cured at $\mathrm{T}=25^{\circ} \mathrm{C}$ and R.H. $=35 \%$, while REF sam- 191 ples were cured at $\mathrm{T}=25^{\circ} \mathrm{C}$ and R.H. $>95 \%$ until testing.

After 28 days of curing, epoxy varnish was applied to screen all rein- 193 forced cylinder surfaces, with the exception of the surface surrounding 194 the exposed rebar region (Fig. 1a). The same screening geometry was 195 adopted for unreinforced samples (Fig. 1b) to produce similar chloride 196 penetration paths.

After the same curing time, physical-mechanical properties such as 198 bulk density, compressive strength, dynamic elastic modulus and mor- 199 tar shrinkage were investigated. In particular, bulk density $\left(\rho\right.$ in $\left.\mathrm{g} / \mathrm{cm}^{3}\right) 200$ was determined from mass/apparent volume ratio. Compressive 201 strengths $\left(\sigma_{\mathrm{c}}\right)$ were measured by an Amsler-Wolpert machine (maxi- 202 mum load: $100 \mathrm{kN}$ ) at a constant displacement rate of $50 \mathrm{~mm} / \mathrm{min} .203$ The results are reported as average values of 5 measurements. Dynamic 204 elastic modulus $\left(E_{d}\right)$ was calculated as an average of 3 measurements, 205 according to the formula $E_{d}=\rho \cdot V^{2}$, where $V$ is the ultrasonic pulse 206 

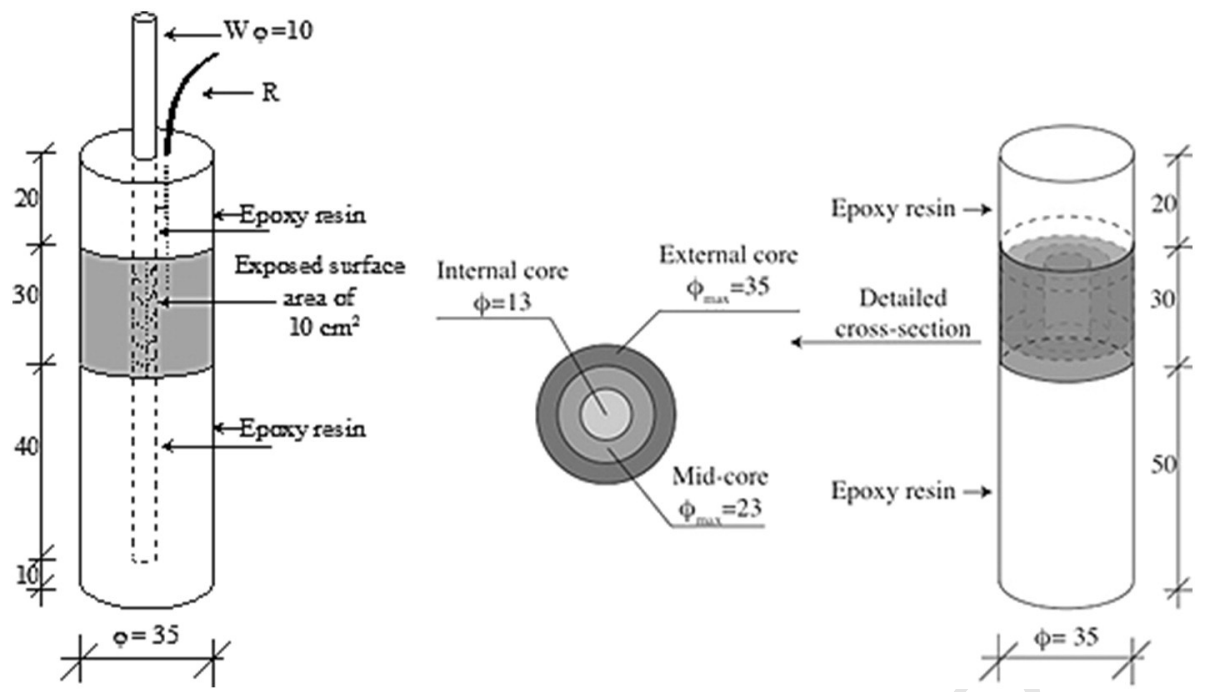

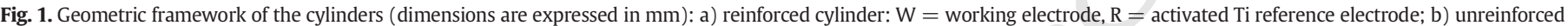
cylinder with detailed cross-section for $\mathrm{Cl}$-analysis.

velocity, measured by a Matest instrument with $55 \mathrm{kHz}$ transducers. The mortar shrinkage was determined according to EN 12617-4 [23].

The mortar microstructure, in terms of pore size distribution, was studied by a mercury intrusion porosimetry (MIP) (Carlo Erba 2000) equipped by a macropore unit (Model 120, Fison Instruments). A mercury surface tension of $0.48 \mathrm{~N} / \mathrm{m}$ and a contact angle of $141.3^{\circ}$ were assumed [24].

Mortar cubes were prepared according to ASTM C1556 [25], in order to evaluate chloride diffusion coefficients, which depend on total volume, dimensions and tortuosity of the mortar pores. After 28 days of curing, the cube surfaces were dried and sealed according to the standard method. Then, they were saturated in calcium hydroxide (REF) or sodium hydroxide solutions (geopolymers), before exposure to $165 \mathrm{~g} / \mathrm{l} \mathrm{NaCl}$ for 38 days. The chloride concentrations at eight recommended depth intervals were determined on powdered mortar samples according to ASTM C1152/C1152M [26] and ASTM C114 [27], while apparent chloride diffusion coefficients $\left(D_{a}, \mathrm{~m}^{2} / \mathrm{s}\right)$ were calculated by fitting the chloride profiles to the error-function solution to Fick's second law.

\subsection{Exposure conditions}

Reinforced and unreinforced cylindrical samples were exposed to 11 weekly w/d cycles. Each cycle consisted in 4 days of immersion in $0.1 \mathrm{M} \mathrm{NaCl}$ solution and 3 days of drying under laboratory conditions $\left(\mathrm{T}=21{ }^{\circ} \mathrm{C}, \mathrm{R} . \mathrm{H} .=35 \%\right)$. The $\mathrm{NaCl}$ solution was periodically refilled by distilled water and renewed each two cycles to avoid any possible change of concentration.

\section{4. $\mathrm{pH}$ and chloride content measurements}

At intervals, during the exposure, unreinforced cylinders were cut and drilled to obtain three coaxial cores, with different maximum diameter, $\Phi_{\max }$ (Fig. 1b).

After 2 and $11 \mathrm{w} / \mathrm{d}$ cycles, mortar portions coming from the innermost mortar cores were ground for $\mathrm{pH}$ measurements. In particular, $5 \mathrm{~g}$ of these mortar specimens was mixed with $5 \mathrm{~cm}^{3}$ distilled water at RT and the pH of the obtained leachate solution was deemed to be an acceptable approximation of the $\mathrm{pH}$ of the mortar pore electrolyte $[11,28]$. Each pH value was the average of three measurements. Reference $\mathrm{pH}$ values were collected just after 28 days of curing. Geopolymer specimens for $\mathrm{pH}$ control were cured in plastic bags to avoid any $\mathrm{pH}$ drift due to carbonation.
After 2, 4, 6, 8 and $11 \mathrm{w} / \mathrm{d}$ cycles, the total chloride concentrations 246 were also measured in all three coaxial cores obtained from each unre- 247 inforced cylinder, according to standard methods [26,27].

2.5.1. Potentiostatic $R_{p}$ measurements

Electrochemical tests were performed on reinforced cylindrical sam- 251 ples exposed to $\mathrm{w} / \mathrm{d}$ cycles. Corrosion potential $\left(\mathrm{E}_{\mathrm{cor}}\right)$ and potentiostatic 252 polarization resistance $\left(R_{p}\right)$ measurements were obtained by a $273 \mathrm{~A} 253$ PAR instrument, mainly during the wet step of the cycles. $E_{\text {cor }}$ values 254 were measured both versus the inner Ti quasi-reference electrode and 255 versus an external saturated calomel electrode (SCE), placed beside 256 the mortar surface close to the bare rebar surface. During potentiostatic 257 tests, a coaxial stainless steel net was positioned around the cylinders 258 and acted as a counter electrode. For measurements carried out in the 259 dry stage of the cycles, the external stainless steel net was secured 260 around the mortar cylinder with an interlaying wet pad to facilitate 261 the electrical contact. The wet pad also permitted $\mathrm{E}_{\text {cor }}$ measurements 262 versus an externally applied SCE. The $R_{p}$ values were obtained by 263 imposing an anodic polarization of $+10 \mathrm{mV}$ versus $\mathrm{E}_{\text {cor }}$ for $300 \mathrm{~s}$ and 264 by dividing this anodic overvoltage by the stable anodic current finally 265 measured. Corrections for IR drop were not necessary because, as 266 assessed by electrochemical impedance spectroscopy (EIS), the ohmic 267 drop between the working and the inner reference electrodes was al- 268 ways negligible with respect to $R_{p}$ values.

\subsubsection{Electrochemical impedance spectroscopy tests}

EIS spectra were collected at selected times, during the wet stage of 271 the w/d cycles, by a Solartron apparatus (EI 1287, FRA 1260), combined 272 with Zview software package. EIS measurements were performed at $\mathrm{E}_{\mathrm{cor}} 273$ with ac perturbation $\pm 10 \mathrm{mV}$ and 5 measurements per decade. Spectra 274 distortions at high frequencies ( $h f$ ), likely connected to mortar non- 275 homogeneities [29], restricted the frequency investigation in the range 276 between $10^{4} \mathrm{~Hz}\left(10^{5} \mathrm{~Hz}\right.$ for some spectra in geopolymers) and 277 $10^{-3} \mathrm{~Hz}$. The $h f$ limitations prevented the analysis of the mortar dielec- 278 tric properties.

\subsubsection{Polarization curves}

After 8,43 and (in the case of REF) 100 days of exposure, in the wet 281 stage of the w/d cycles, ohmic drop-compensated polarization curves 282 were recorded, in order to better characterize the corrosion conditions 283 
of the rebars. They were recorded at a scan rate of $0.166 \mathrm{mV} \mathrm{s}^{-1}$, always starting from $\mathrm{E}_{\mathrm{cor}}$.

\subsection{Corrosion product analysis}

At the end of the exposure period, rebars not used for polarization curve recording were extracted from the mortars for visual observation and Raman analysis of surface corrosion products. Raman spectra were collected by a Renishaw Raman Invia instrument, under conditions that avoided the thermal degradation of iron compounds. An Ar + laser $(514.5 \mathrm{~nm})$ was adopted, with integration time $(\mathrm{t})$ of $10 \mathrm{~s}$, number of accumulations ( $\mathrm{n}$ ) of 4 and laser power (Pout) of $3 \mathrm{~mW}$.

\section{Results}

\subsection{Mortar characterization}

Bulk density results, together with compressive strengths, elastic moduli and shrinkage values collected after 28 days of curing are reported in Table 1 . These data evidence that REF mortar shows better mechanical performances and stability than geopolymers. In fact, it exhibits higher compressive strength values, higher $\mathrm{E}_{\mathrm{d}}$ modulus and almost no shrinkage. Among geopolymers, G_1 has the best properties, in agreement with the information already available in the literature suggesting that the mechanical resistance of geopolymers increases at decreasing $\mathrm{Na}_{2} \mathrm{O} / \mathrm{SiO}_{2}$ molar ratios [10,19]. G_1 shows a compressive strength value of $34.2 \pm 2.9 \mathrm{MPa}$ and can be classified as a 32.5 strength class binder, according to EN 196-1 [22]. With regard to shrinkage, a $-0.3 \%$ variation was observed in $G \_1$ and $G \_2$, while a $-0.1 \%$ was observed in G_3 mortar, which is the most stable geopolymeric formulation. The different curing conditions adopted for geopolymers $\left(\mathrm{T}=25{ }^{\circ} \mathrm{C}\right.$ and R.H. $\left.=35 \%\right)$ and cement-based mortar $\left(\mathrm{T}=25^{\circ} \mathrm{C}\right.$ and R.H. > 95\%) partially explain the different shrinkage behaviour of geopolymers and REF. Shrinkage values for geopolymers higher than those usually exhibited by cement based mortars were already reported. This behaviour was also ascribed to loss of water from unreacted porous FA particles and to pore size distribution and relevant interconnectivity [30,31].

In order to justify the different physical-mechanical properties of REF and geopolymers, MIP was used to determine the pore distribution curves of the different mortars (Fig. 2). The total specific $\mathrm{Hg}$ volume intruded in geopolymer mortars, and particularly in G_3, was higher than that in REF, suggesting a higher total porosity and a greater vulnerability of geopolymers to degradation. More in detail, the pore size distribution curves of G_3 show the highest total porosity of about $85 \mathrm{~mm}^{3} / \mathrm{g}$ (inducing the low measured bulk density of this mortar) and a bimodal pore size distribution positioned at about $1 \mu \mathrm{m}$ and in the range $0.3-0.03 \mu \mathrm{m}$. The pore distribution curves of $G_{-} 1$ and $G \_2$ are rather similar to each other and are characterized by a total porosity of 57$60 \mathrm{~mm}^{3} / \mathrm{g}$ and pore radii mostly around $1-3 \mu \mathrm{m}$. In the case of REF, the total porosity is smaller (about $50 \mathrm{~mm}^{3} / \mathrm{g}$ ) and mainly consists in pores smaller than $0.5 \mu \mathrm{m}$ and nanometric gel pores. As pores exceeding $1 \mu \mathrm{m}$ are directly responsible for the rate of mass transfer through the porous system, the REF pore network will induce slower water saturation and mass transfer processes.

Table 1

Physical-mechanical characterization of the considered mortars after 28 days of curing.

\begin{tabular}{lllll}
\hline Sample & $\begin{array}{l}\text { Bulk density } \\
\left(\mathrm{g} / \mathrm{cm}^{2}\right)\end{array}$ & $\begin{array}{l}\text { Compressive } \\
\text { strength }(\mathrm{MPa})\end{array}$ & $\begin{array}{l}\text { Dynamic elastic } \\
\text { modulus }(\mathrm{GPa})\end{array}$ & Shrinkage (\%) \\
\hline $\mathrm{G} \_1$ & $2.11 \pm 0.01$ & $34.2 \pm 2.9$ & $15.6 \pm 1.7$ & $-0.36 \pm 0.13$ \\
$\mathrm{G} \_2$ & $2.07 \pm 0.01$ & $27.0 \pm 3.1$ & $15.9 \pm 2.5$ & $-0.37 \pm 0.02$ \\
$\mathrm{G}$ _3 & $1.78 \pm 0.13$ & $22.5 \pm 0.8$ & $14.2 \pm 2.2$ & $-0.11 \pm 0.02$ \\
REF & $2.11 \pm 0.02$ & $47.0 \pm 5.7$ & $30.2 \pm 2.2$ & $-0.02 \pm 0.01$ \\
\hline
\end{tabular}

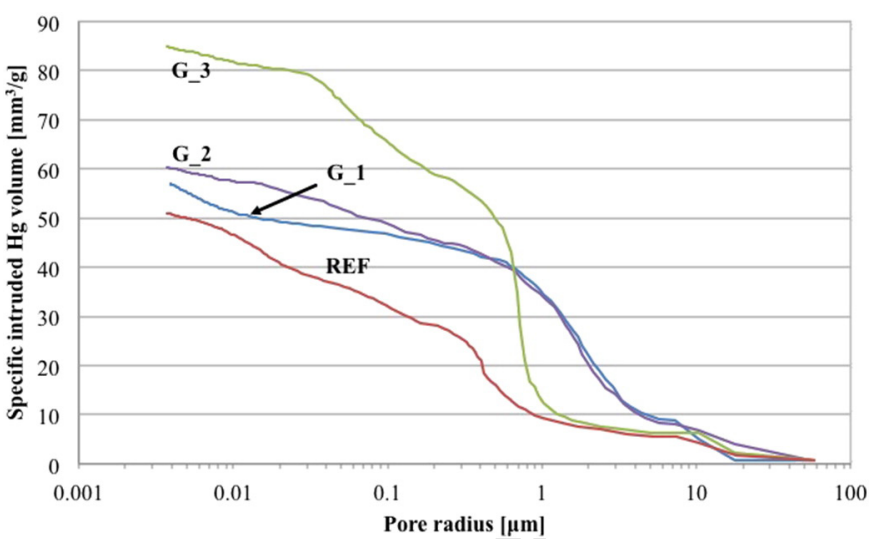

Fig. 2. Pore size distribution curves at 28 days of curing.

Apparent chloride diffusion coefficients, $\mathrm{D}_{\mathrm{a}}$, were also measured in 334 the different mortars under fully saturated conditions to evaluate the 335 relative chloride mobility under pure diffusion conditions, which is 336 affected by pore dimensions, tortuosity and interconnectivity in the dif- 337 ferent porous systems. $\mathrm{D}_{\mathrm{a}}$ of REF is smaller than those of geopolymers, 338 which in turn increase going from G_1 to G_2 and G_3 (Table 2). The 339 last value is one order of magnitude higher than that of REF. $\mathrm{D}_{\mathrm{a}}$ data 340 appear in good agreement with total porosity values.

\section{2. $\mathrm{pH}$ and chloride content measurements}

Table 3 collects the $\mathrm{pH}$ of the pore electrolytes measured in the core 343 of unreinforced cylinders after 28 days of curing in the absence of car- 344 bonation (curing in plastic bags for geopolymers, normal curing for 345 $\mathrm{REF}$ ) and after 2 and $11 \mathrm{w} / \mathrm{d}$ cycles. The initial values obtained in the ab- 346 sence of carbonation in G_1 and G_2 are similar to those obtained in REF 347 (12.80-12.97). Instead, $\mathrm{G}_{-} 3$ exhibits a higher $\mathrm{pH}$ value (13.25), likely 348 connected to the high $\mathrm{Na}_{2} \mathrm{O}$ content in the activating solution. $\quad 349$

During the $\mathrm{w} / \mathrm{d}$ cycles, all FA mortar cylinders underwent a signifi- 350 cant carbonation process. In particular, Table 3 evidences that the $\mathrm{pH} 351$ of the pore electrolyte in the cylinder cores decreased to about 12352 after 14 days ( 2 cycles) and dropped to a common limit of 10.5-10.8, 353 after 77 days ( 11 cycles). In contrast, the $\mathrm{pH}$ always remained well 354 over 12 in the case of REF samples. This different behaviour is due to 355 the formation of different reaction products after the reaction of the 356 penetrated $\mathrm{CO}_{2}$ with the alkaline components of the mortars: soluble 357 sodium carbonate salts in geopolymers and insoluble calcium carbon- 358 ate, capable to partially obstruct the mortar pores and to slow down 359 the $\mathrm{CO}_{2}$ penetration, in the case of REF [32]. The phenolphthalein test 360 for carbonation depth assessment applied on the mortar cylinders 361 after 14 days ( 2 cycles) (Fig. 3 ) confirmed that after this exposure 362 time the cylinder cores were not carbonated. It also evidenced that no 363 carbonation affected REF, while the carbonation depth decreased 364 going from G_1 to G_2 and G_3 that is at increasing $\mathrm{Na}_{2} \mathrm{O} / \mathrm{SiO}_{2}$ ratio in 365 the activating solution. This suggests that a high $\mathrm{Na}_{2} \mathrm{O}$ content can 366 slightly slow down the carbonation rate.

The application of the standard ASTM method for the measurement 368 of total chloride content in mortars after 2, 4, 6, 8, 11 w/d cycles 369

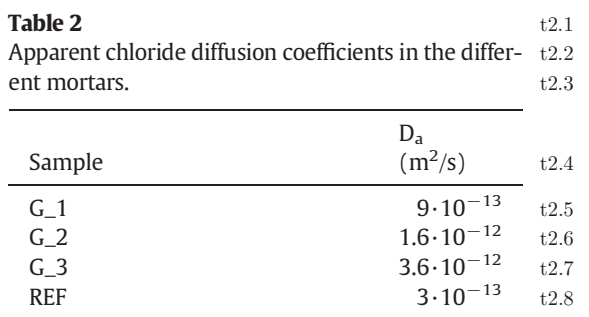


Table 3

$\mathrm{pH}$ measurements for the investigated mortar samples.

\begin{tabular}{llll}
\hline Sample & pH after 28 d curing & pH after 2 w/d cycles & pH after 11 w/d cycles \\
\hline G_1 & $12.80^{\mathrm{a}}$ & 11.89 & 10.76 \\
G_2 & $12.90^{\mathrm{a}}$ & 11.96 & 10.54 \\
G_3 & $13.25^{\mathrm{a}}$ & 12.07 & 10.72 \\
REF & 12.97 & 12.66 & 12.18 \\
\hline
\end{tabular}

a Curing in plastic bag, to assess initial $\mathrm{pH}$ in the absence of carbonation.

evidenced that chloride concentration was always independent of the depths in all mortar types. For this reason, Fig. 4 collects the average chloride contents measured inside the mortars, as a function of exposure time. In REF, the chloride content strongly augmented with time, reaching a concentration of $0.75 \mathrm{wt} . \%$ (vs binder) after $11 \mathrm{w} / \mathrm{d}$ cycles, while in FA samples, the average chloride content remained more or less constant during the exposure period, in the range of 0.06$0.18 \mathrm{wt} . \%$, independently of the specific geopolymer considered. This different trend can be connected to differences in chloride binding capacity of the two mortar systems. In cement-based mortar, chlorides form low solubility calcium-containing compounds (e.g., Friedel salts, FS, calcium salts), while in geopolymers calcium content is low and the prevailing sodium chloride salt is characterized by a much higher leachability.

\subsection{Electrochemical tests}

\subsubsection{Potentiostatic $R_{p}$ measurements}

Fig. 5 collects representative time trends of $E_{c o r}$ and $R_{p}$ values obtained in G_1 (a), G_2 (b), G_3 (c) and REF (d) mortars, during w/d cycles in $0.1 \mathrm{M} \mathrm{NaCl}$ solution. All of them clearly evidence the time at which rebar depassivation was achieved. In fact, initially, the rebar $\mathrm{E}_{\mathrm{cor}}$ values were quite noble. They oscillated in the range $-0.15 /-0.06 \mathrm{~V}_{\mathrm{SCE}}$ for $\mathrm{G}_{-} 3$ and REF, while showed an increasing trend from about -0.17 to $-0.10 V_{S C E}$, in the case of $G_{-} 1$ and $G_{-}$2. During this first period, $R_{p}$ values of about $1 \mathrm{M} \Omega \mathrm{cm}^{2}$ or higher were recorded, with the highest values recorded in FA mortars. After 12-18 days, the $\mathrm{E}_{\mathrm{cor}}$ values in geopolymers started to decrease and reached values of $-0.60 \mathrm{~V}_{\mathrm{SCE}}$ or more negative, while $R_{p}$ values diminished progressively down to $1 \mathrm{k} \Omega \mathrm{cm}^{2}$, indicating the onset and propagation of a corrosion attack. In REF, the $\mathrm{E}_{\mathrm{cor}}$ values of rebars started to decrease after longer exposure periods (longer than 40 days) and a concomitant sharp $\mathrm{R}_{\mathrm{p}}$ drop was recorded, but afterwards the rebars again underwent repassivation/depassivation events, as denoted by the concurrent $\mathrm{E}_{\mathrm{cor}} / \mathrm{R}_{\mathrm{p}}$ oscillations (Fig. $5 \mathrm{~d}$ ).

Corrosion in REF is connected to the penetration of chlorides (Fig. 4) that, after exposures of 42 days, arrive at concentrations of $0.43 \%$ (vs binder) and at the end of the exposure period reach concentrations of $0.75 \%$ (vs binder). These chloride levels are comparable or higher than those reputed critical for the onset of corrosion in traditional noncarbonated mortars [33]. In geopolymers, in spite of the smaller

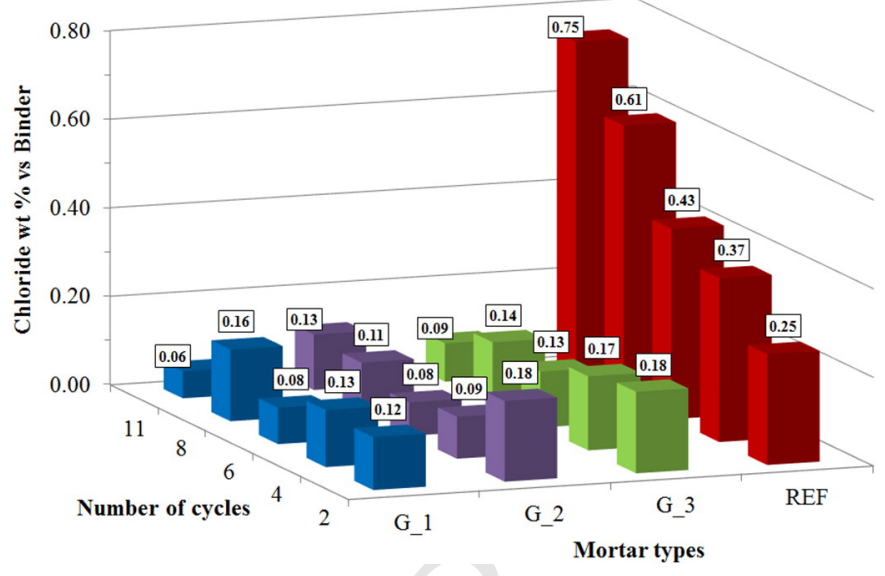

Fig. 4. Average total chloride contents (wt.\% vs binder) in the investigated mortar samples after different exposure cycles.

amounts of penetrated chlorides, rebar depassivation was detected at 408 shorter times. This is reasonably connected to the quick mortar carbon- 409 ation, which decreased the mortar $\mathrm{pH}$ and for this reason reduced the 410 critical chloride contents for the onset of corrosion. However, in 411 geopolymers a low calcium content is present which is expected to re- 412 duce the formation of insoluble chloride salts, so increasing the fractions 413 of free to total chloride concentrations. Therefore, in spite of the low de- 414 tected total chloride contents, relatively high amounts of aggressive free 415 chlorides cannot be excluded.

Fig. 6 shows the relationship between $R_{p}$ and $E_{\text {cor }}$ for the different 417 mortars, independently of exposure time. As expected from Fig. 5, 418 higher $\mathrm{R}_{\mathrm{p}}$ mainly corresponded to nobler $\mathrm{E}_{\mathrm{cor}}$ values in all mortars and 419 time evolution, indicated in the Figure, confirmed progression towards 420 rebar corrosion, in the timeframe of the tests here described. However, 421 in geopolymers passive conditions (that is conditions with noble $\mathrm{E}_{\text {cor }} 422$ values) corresponded to higher $\mathrm{R}_{\mathrm{p}}$, in comparison to REF. This was likely 423 connected to the relevant amounts of silicates present in the pore elec- 424 trolyte of geopolymers, which could slightly inhibit the corrosion pro- 425 cess and reinforce passivity, as found in a previous research [10]. As a 426 result, the linear trends fitting $\log R_{p} / E_{\text {cor }}$ values in $G_{-} 1$ and $G_{-} 2427$ (Fig. 6) had higher slopes than that of REF. In the case of G_3, the 428 rebar behaviour was the same detected in G_1 and G_2 at the beginning 429 of the test (that is under passive conditions), but during depassivation 430 $R_{p}$ values higher than those measured in the other geopolymers were 431 detected. When severe corrosion conditions were reached (green dia- 432 monds with the more negative $E_{\text {cor }}$ values in Fig. 6), the $R_{p}$ of the rebars 433 in $G_{-} 3$ became similar to those found in the other geopolymers. The rel- 434 atively high $\mathrm{R}_{\mathrm{p}}$ values detected in this geopolymer for some time during 435 depassivation are likely connected to its high $\mathrm{Na}_{2} \mathrm{O}$ content, which can 436

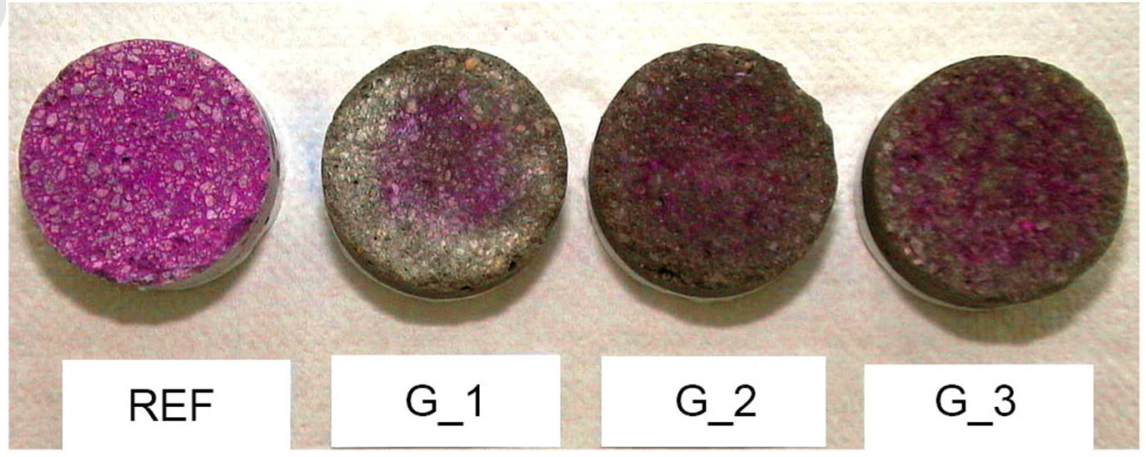

Fig. 3. Carbonation depth assessment (by phenolphthalein method) on sectioned mortar cylinders exposed for 14 days ( 2 cycles) to the $0.1 \mathrm{M}$ NaCl solution. 


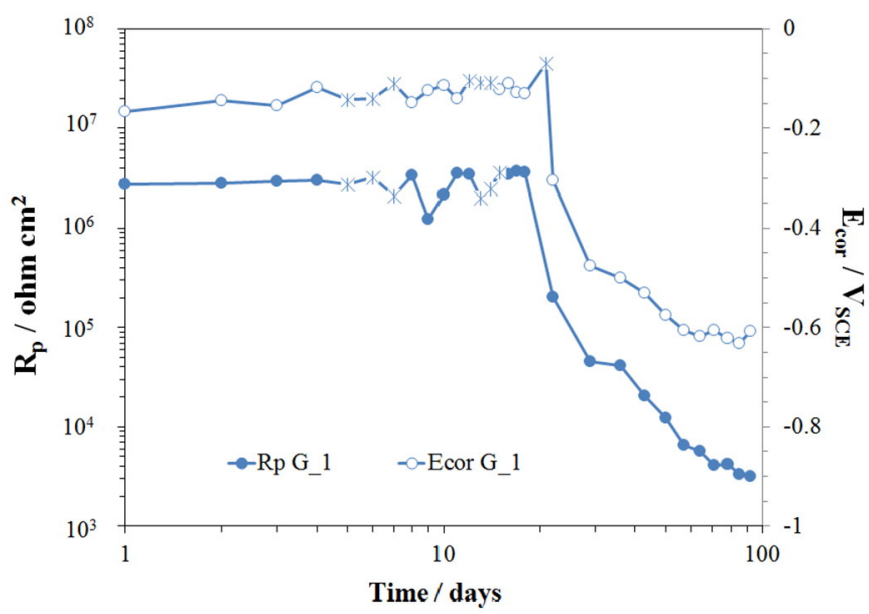

a)

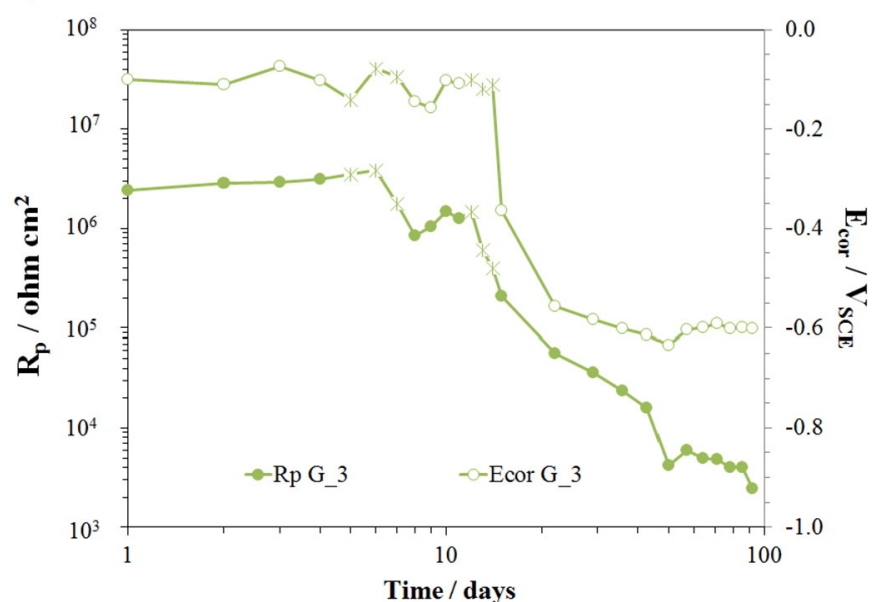

c)

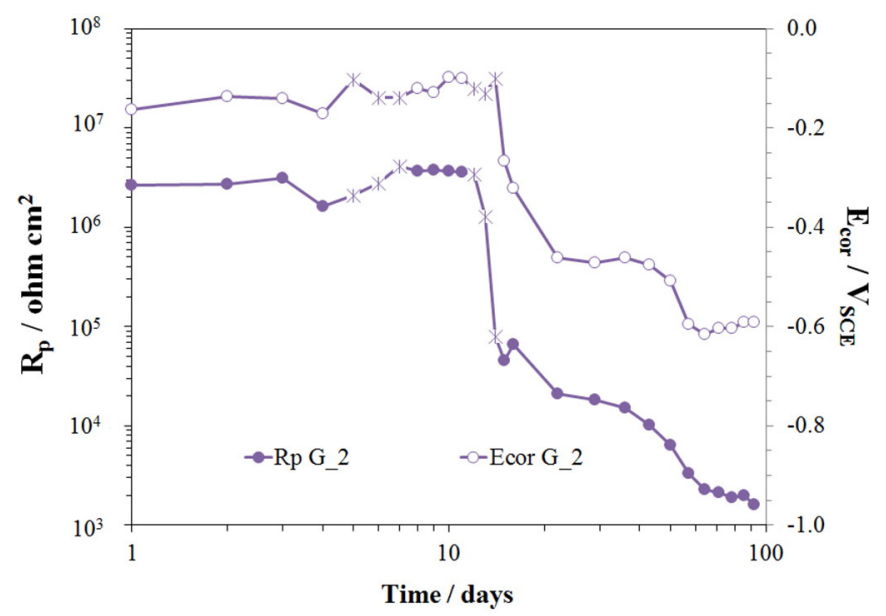

b)

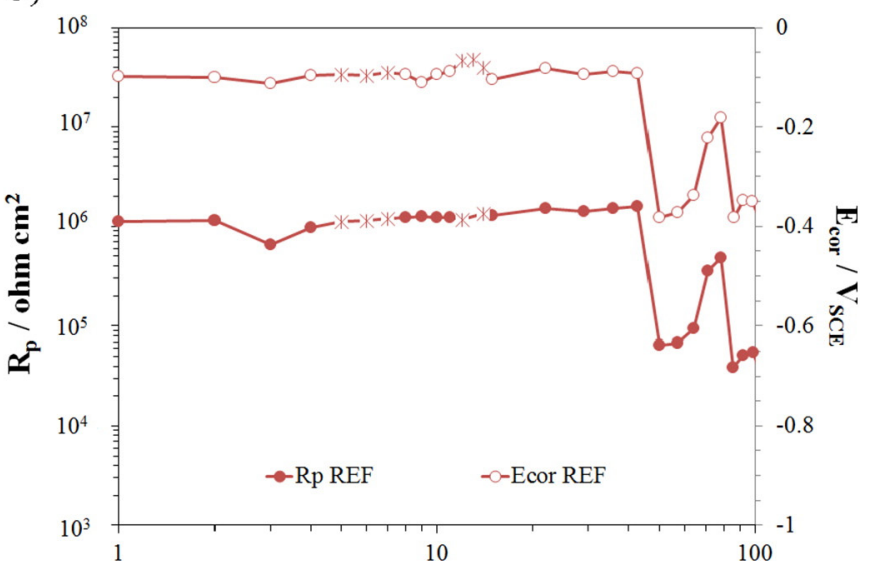

Time / days

d)

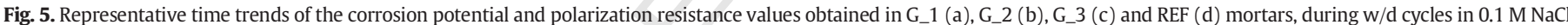
solution. Most data were obtained during the wet step of the cycles. Those collected in the dry step are indicated by the symbol *.

slow down carbonation and $\mathrm{pH}$ diminution and, for a while, can favour slightly lower corrosion rates.

Fig. 6 describes the $R_{p} / E_{\text {cor }}$ dependence during depassivation, but it does not give any information about the speed of depassivation. In order to compare the depassivation rate in the different mortar types

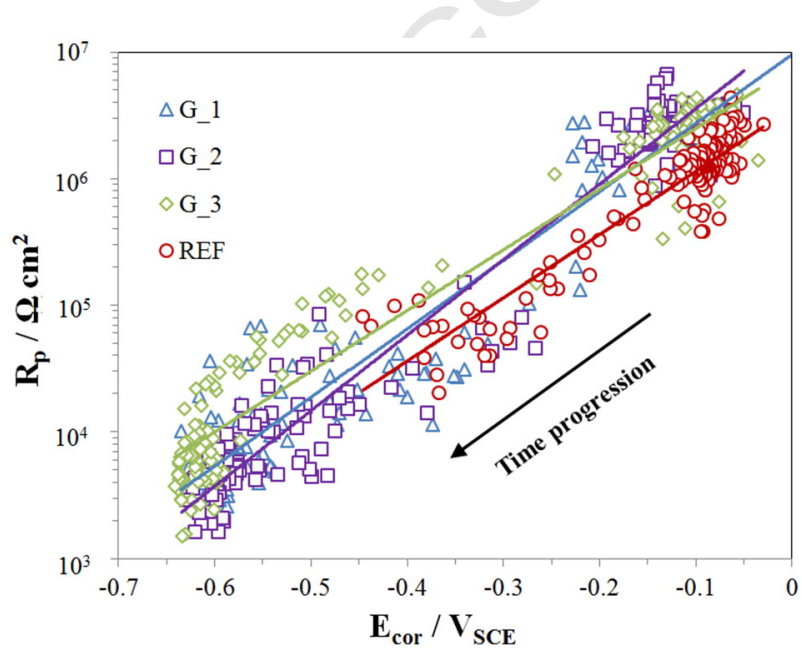

Fig. 6. Relations between $\mathrm{R}_{\mathrm{p}}$ and $\mathrm{E}_{\mathrm{cor}}$ measured during $\mathrm{w} / \mathrm{d}$ exposures in the different mortars. on a statistical basis, Fig. 7 shows the time evolution of the fraction of re- 442 bars with corrosion probability greater than $90 \%$, that is the fraction of 443 rebars characterized by $\mathrm{E}_{\text {cor }}$ values more negative than $-0.276 \mathrm{~V}_{\mathrm{SCE}} 444$ [27]. The figure clearly evidences that REF offers the highest corrosion 445 protection to the reinforcements, as an exposure period longer than 446

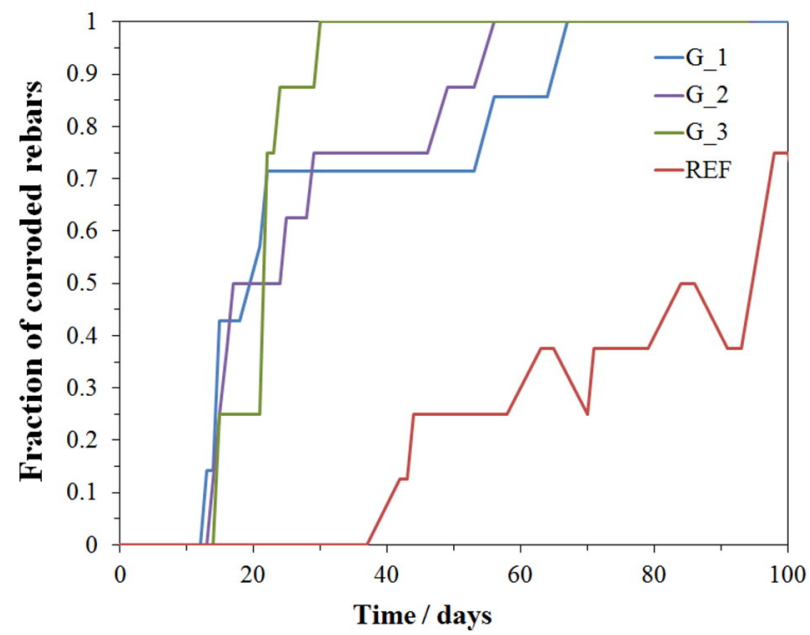

Fig. 7. Time dependence of the rebar fractions affected by corrosion in the different mortars during $\mathrm{w} / \mathrm{d}$ cycles in $0.1 \mathrm{M} \mathrm{NaCl}$ solution. 


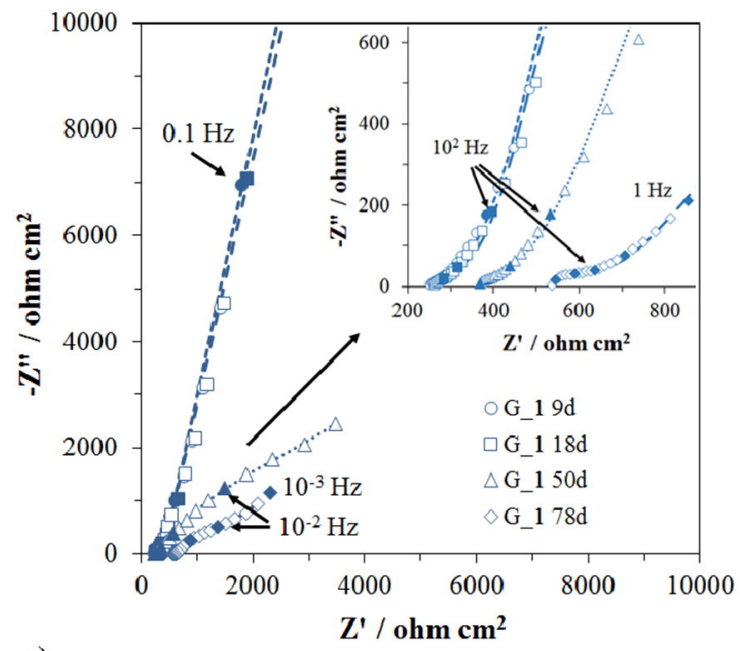

a)

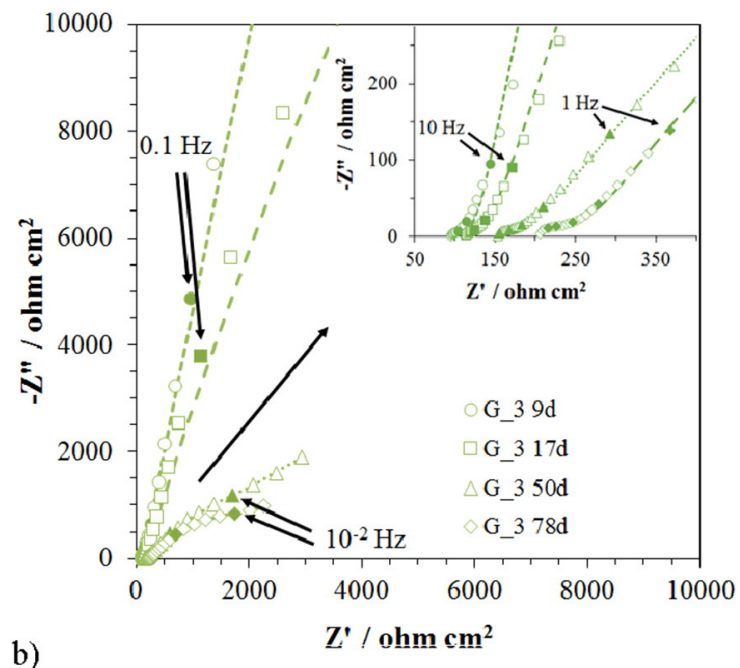

b)

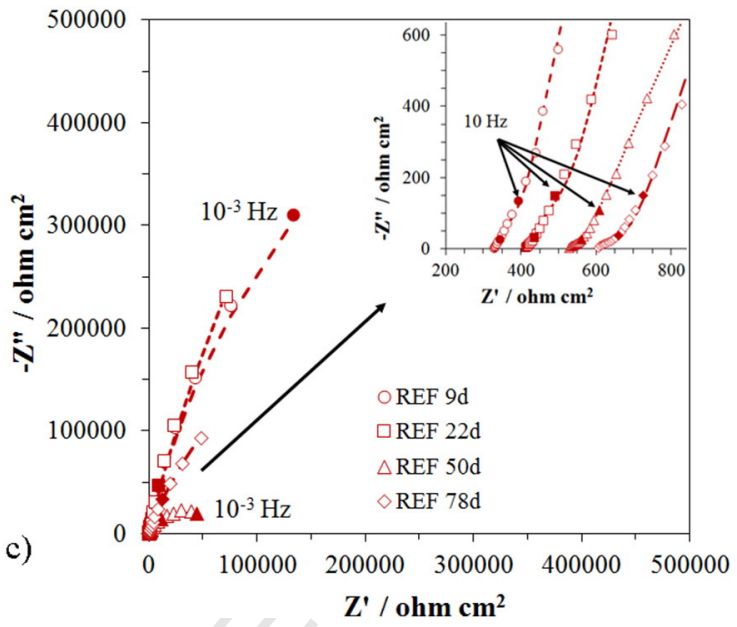

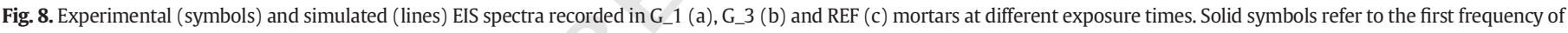
each decade.

95 days is necessary to induce corrosion attack on more than $50 \%$ of the rebars. In the case of geopolymers this occurs after about 20 days. In G_1 and $G \_2$, corrosion propagates in all rebars after about 60 days, while in G_3 this occurs after only 25 days. This suggests that the high G_3 porosity (Fig. 2) permits a faster oxygen diffusion (and faster corrosion) and contrasts the positive effects of a slower carbonation rate.

\subsubsection{Electrochemical impedance spectroscopy}

The EIS spectra collected in G_1 and G_3 geopolymers at different exposure times are shown in Fig. $8 \mathrm{a}$ and $\mathrm{b}$ in the form of Nyquist plots. Those obtained in $\mathrm{G}_{2} 2$ are quite similar and have not been shown.

Before the onset of corrosion, identified by $\mathrm{R}_{\mathrm{p}}$ and $\mathrm{E}_{\mathrm{cor}}$ drops (Fig. 5), the spectra comprised two capacitive loops. The first one, at frequencies higher than $10^{2} \mathrm{~Hz}$, was very small and often ill-resolved, particularly at short immersion times (boxes in Fig. 8a,b). Different interpretations were given to it (film of corrosion products [34], presence of a cementi- 461 tious film on the rebar surface, with specific characteristics different 462 from that of bulk mortars [35,36]). As its presence was observed since 463 the beginning of the exposures, when the rebars were still passive, the 464 last interpretation connecting it to dielectric properties of an interfacial 465 geopolymeric region appears correct. The second capacitive arc at 466 frequencies lower than $10^{2}-10 \mathrm{~Hz}$ was connected to charge transfer 467 reactions on the rebar surface.

These spectra were reasonably well fitted by the equivalent circuit 460 (EC) in Fig. 9a [9,37-39] and the obtained simulated curves are 470 superimposed on the experimental spectra of Fig. 8. The first element 471 in the EC is the resistance $\mathrm{R}_{\mathrm{s}}+\mathrm{m}$, which corresponds to the sum of the 472 pore electrolyte and mortar resistance between the pseudo-reference 473 Ti electrode and the steel surface. Then, the EC shows two parallel com- 474 binations of a resistance ( $R$ ) and a constant phase element (CPE), in 475

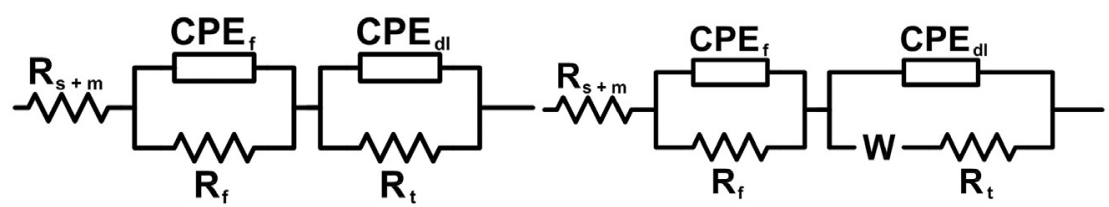

a)

b)

Fig. 9. Equivalent circuits used to fit EIS spectra: a) under passive conditions or limited corrosion attack; b) under active corrosion conditions. 
series to each other. The first combination $\left(\mathrm{R}_{\mathrm{f}}-\mathrm{CPE}_{\mathrm{f}}\right.$ arm $)$ fits the $h f$ shoulder connected to the presence of the interface mortar film [38], while the low frequency (lf) combination $\left(R_{t}-C P E_{d l}\right)$ is linked to the charge transfer resistance and double layer capacitance and gives information on the corrosion process. In EC, the substitution of capacitances with Constant Phase Elements (CPE) aims at complying with inhomogeneities and discontinuities at interfaces. CPE is a distributed element with impedance expression:

$\mathrm{Z}_{\mathrm{CPE}}=\left[\mathrm{Y}(\mathrm{j} \omega)^{n}\right]^{-1}$

where $\mathrm{Y}(\mathrm{j} \omega)^{\mathrm{n}}$ is an admittance, $\mathrm{j}$ is the imaginary unit, $\omega$ is the angular frequency, $0 \leq \mathrm{n} \leq 1$ (for $\mathrm{n}=0$ CPE stands for a resistance, while for $\mathrm{n}=$ 1 it is a pure capacitance).

In the presence of a severe corrosion attack (very negative $\mathrm{E}_{\text {cor }}$ and low potentiostatic $R_{p}$ values), impedance spectra were characterized by three capacitive arcs (Fig. 8a,b). Beside the $h f$ one, related to the interfacial mortar film, two other arcs were present, connected to charge transfer (the medium frequency, $m f$, arc) and mass transfer (If arc) processes. These spectra were correctly fitted by the EC of Fig. 9b [9,37,39, 40], where in the $\mathrm{R}_{\mathrm{t}}-\mathrm{CPE}_{\mathrm{dl}}$ arm a Finite-Length Warburg element (W) was introduced to take into account the influence of diffusion on corrosion:

$\mathrm{W}=\mathrm{R}_{w} \cdot \frac{\tanh \left[\mathrm{j} \omega\left(\frac{\delta^{2}}{\mathrm{D}}\right)\right]^{P}}{\left[\mathrm{j} \omega\left(\frac{\delta^{2}}{\mathrm{D}}\right)\right]^{\mathrm{P}}}$

where $\delta$ is the effective diffusion path length, D the effective diffusion coefficient and $0 \leq \mathrm{P} \leq 1[39,41]$.

The fitting parameters related to all geopolymer spectra are reported in Tables $4-6 . R_{s}+m$ values are always very small, in the range 70$500 \Omega \mathrm{cm}^{2}$, given the position of the reference electrode in close proximity of the steel electrode, and tend to increase with time, likely due to the going on of the mortar curing. As the chloride content in the mortars is more or less constant with time, also the observed increase with time of the geopolymeric interfacial film resistance $\left(R_{f}\right)$ could be connected to the time evolution of the mortar compactness. The pore obstruction with corrosion products in the proximity of the rebars could give a further contribution to $R_{f}$ increase at times longer than 20 days. Differences in $R_{s}+m$ and $R_{f}$ among geopolymers confirm the higher compactness of G_1 in comparison to the other FA mortar formulations. At short exposure periods, $\mathrm{R}_{\mathrm{t}}$ values are higher (and often much higher) than $1 \mathrm{M} \Omega \mathrm{cm}^{2}$, meaning that charge transfer through the surface passive films controls the corrosion rates. When $\mathrm{E}_{\mathrm{cor}}$ values become more negative and set within $-0.3 /-0.6 \mathrm{~V}_{\mathrm{SCE}}, \mathrm{R}_{\mathrm{t}}$ values decrease concurrently, down to some $\mathrm{k} \Omega \mathrm{cm}^{2}$ and double layer pseudo capacitances significantly increase up to a few $\mathrm{m}^{-1} \mathrm{~cm}^{-2} \mathrm{~s}^{\text {ndl }}$. These variations are connected, respectively, to the decrease of surface oxide film protectiveness and to the increase in real surface area of corroded rebars. Under
Table 5

Fitting parameters of EIS spectra and related $\mathrm{E}_{\mathrm{cor}}$ values, obtained in G_2 mortar.

\begin{tabular}{|c|c|c|c|c|c|}
\hline Time/days & 2 & 9 & 16 & 50 & 78 \\
\hline $\mathrm{E}_{\mathrm{cor}} / \mathrm{V}_{\mathrm{SCE}}$ & -0.137 & -0.128 & -0.322 & -0.596 & -0.606 \\
\hline $\mathrm{R}_{\mathrm{s}}+\mathrm{m} / \Omega \mathrm{cm}^{2}$ & 124 & 140 & 143 & 227 & 423 \\
\hline $\mathrm{R}_{\mathrm{f}} / \Omega \mathrm{cm}^{2}$ & 40 & 70 & 53 & 40 & 100 \\
\hline $\mathrm{Y}_{\mathrm{f}} / \mu \Omega^{-1} \mathrm{~cm}^{-2} \mathrm{~s}^{\mathrm{nf}}$ & 800 & 800 & 800 & 700 & 226 \\
\hline $\mathrm{n}_{\mathrm{f}}$ & 0.53 & 0.5 & 0.5 & 0.5 & 0.5 \\
\hline $\mathrm{R}_{\mathrm{t}} / \mathrm{k} \Omega \mathrm{cm}^{2}$ & 5300 & 10,000 & 40.5 & 3.8 & 1.36 \\
\hline $\mathrm{R}_{\mathrm{W}} / \mathrm{k} \Omega \mathrm{cm}^{2}$ & & - & - & 4.42 & 2.00 \\
\hline$\delta^{2} / \mathrm{D} / \mathrm{s}$ & & - & - & 968 & 673 \\
\hline $\mathrm{P}$ & & - & - & 0.5 & 0.5 \\
\hline $\mathrm{Y}_{\mathrm{dl}} / \mu \Omega^{-1} \mathrm{~cm}^{-2} \mathrm{~s}^{\mathrm{ndl}}$ & 230 & 221 & 316 & 1800 & 2240 \\
\hline $\mathrm{n}_{\mathrm{dl}}$ & 0.88 & 0.87 & 0.8 & 0.6 & 0.57 \\
\hline
\end{tabular}

severe corrosion conditions, the Warburg parameter $\mathrm{R}_{\mathrm{W}}$, representing 518 the resistance to diffusion processes, has always the same magnitude 519 order of $\mathrm{R}_{\mathrm{t}}$, suggesting that corrosion rate is under a mixed charge trans- 520 fer/diffusion control. G_3 presents slightly lower $R_{W}$ and $\left(\delta^{2} / D\right)$ values, 521 likely due to the lower resistance to diffusion and higher diffusion coef- 522 ficient in the most porous G_3 microstructure.

The EIS spectra obtained in REF mortar are collected in Fig. 8c. They 524 are quite similar to those collected in geopolymers before the develop- 525 ment of severe corrosion, suggesting that in this case diffusion phenom- 526 ena do not affect the corrosion rates. Therefore, only the EC of Fig. 9a 527 was adopted to fit the experimental spectra and the results are collected 528 in Table 7. The $R_{s}+m$ are slightly higher than those measured in the 529 most compact geopolymer (G_1), in agreement with the even denser 530 REF microstructure. Also in REF, a continuous increase with time of 531 $R_{s}+m$ and $R_{f}$ values is recorded, in spite of chloride accumulation, due 532 to the prevailing effect of the ongoing mortar curing. The more long 533 lasting protectiveness of REF reflects in the persistence of relatively high 534 $R_{t}$ values till the end of the test and in the capability of steel repassivation, 535 after the onset of a corrosion attack. In fact, after 50 days $R_{t}$ decreases 536 to $60 \mathrm{k} \Omega \mathrm{cm}^{2}$ (and $\mathrm{E}_{\mathrm{cor}}$ diminishes to $-0.38 \mathrm{~V}_{\mathrm{SCE}}$ ) and then, after 537 78 days, it increases again up to $600 \mathrm{k} \Omega \mathrm{cm}^{2}$ (and $\mathrm{E}_{\text {cor }}$ ennobles up 538 to $\left.-0.18 \mathrm{~V}_{\mathrm{SCE}}\right)$.

\subsubsection{Polarization curves}

540

Fig. 10 shows the ohmic drop-compensated polarization curves 541 recorded on reinforcing bars in geopolymers (Fig. 10a) and REF 542 (Fig. 10b). They clearly evidence that at increasing exposure periods, 543 variations in surface film stability (connected to the pore solutions 544 modifications described in Section 3.2) modify the rebar electro- 545 chemical behaviour. In particular, the curves show that after 8 days 546 exposure stable passive films are present in both mortar types, in- 547 ducing noble $\mathrm{E}_{\mathrm{cor}}$ (around $-0.1 \mathrm{~V}_{\mathrm{SCE}}$ ) and low $\mathrm{i}_{\text {cor }}$ values (varying 548 within $0.06-0.1 \mu \mathrm{A} / \mathrm{cm}^{2}$ ). Passive currents are recorded up to potentials 549 of about $+0.6 \mathrm{~V}_{\mathrm{SCE}}$ where an abrupt current increase was observed, due 550 to oxygen evolution [42]. Instead, after 43 days, the polarization curves 551 recorded in geopolymers (Fig. 10a) exhibited much more negative $\mathrm{E}_{\text {cor }} 552$
Table 4

Fitting parameters of EIS spectra and related $\mathrm{E}_{\text {cor }}$ values, obtained in $\mathrm{G} \_1$ mortar.

\begin{tabular}{lcllcc}
\hline Time $/$ days & 2 & 9 & 18 & 50 & 78 \\
\hline $\mathrm{E}_{\mathrm{cor}} / \mathrm{V}_{\mathrm{SCE}}$ & -0.128 & -0.141 & -0.13 & -0.575 & -0.621 \\
$\mathrm{R}_{\mathrm{s}}+\mathrm{m} / \Omega \mathrm{cm}^{2}$ & 165 & 250 & 250 & 360 & 520 \\
$\mathrm{R}_{\mathrm{f}} / \Omega \mathrm{cm}^{2}$ & 64 & 150 & 150 & 220 & 220 \\
$\mathrm{Y}_{\mathrm{f}} / \mu \Omega^{-1} \mathrm{~cm}^{-2} \mathrm{~s}^{\mathrm{nf}}$ & 300 & 370 & 320 & 540 & 360 \\
$\mathrm{n}_{\mathrm{f}}$ & 0.6 & 0.53 & 0.5 & 0.42 & 0.40 \\
$\mathrm{R}_{\mathrm{t}} / \mathrm{k} \Omega \mathrm{cm}^{2}$ & 6000 & 16,000 & 20,000 & 5.26 & 1.86 \\
$\mathrm{R}_{\mathrm{W}} / \mathrm{k} \Omega \mathrm{cm}^{2}$ & & - & - & 5.97 & 2.64 \\
$\delta^{2} / \mathrm{D} / \mathrm{s}$ & & - & - & 500 & 650 \\
$\mathrm{P}$ & & - & - & 0.5 & 0.5 \\
$\mathrm{Y}_{\mathrm{dl}} / \mu \Omega^{-1} \mathrm{~cm}^{-2} \mathrm{~s}^{\text {ndl }}$ & 200 & 200 & 196 & 3740 & 3919 \\
$\mathrm{n}_{\mathrm{dl}}$ & 0.87 & 0.87 & 0.87 & 0.65 & 0.6
\end{tabular}

Table 6

Fitting parameters of EIS spectra and related $E_{\text {cor }}$ values, obtained in $\mathrm{G}_{-} 3$ mortar.

\begin{tabular}{llllcc}
\hline Time $/$ days & 2 & 9 & 17 & 50 & 78 \\
\hline $\mathrm{E}_{\mathrm{cor}} / \mathrm{V}_{\mathrm{SCE}}$ & -0.134 & -0.156 & -0.364 & -0.634 & -0.601 \\
$\mathrm{R}_{\mathrm{s}}+\mathrm{m} / \Omega \mathrm{cm}^{2}$ & 71 & 96 & 114 & 154 & 205 \\
$\mathrm{R}_{\mathrm{f}} / \Omega \mathrm{cm}^{2}$ & 15 & 34 & 35 & 51 & 69 \\
$\mathrm{Y}_{\mathrm{f}} / \mu \Omega^{-1} \mathrm{~cm}^{-2} \mathrm{~s}^{\mathrm{nf}}$ & 600 & 600 & 821 & 878 & 463 \\
$\mathrm{n}_{\mathrm{f}}$ & 0.6 & 0.5 & 0.5 & 0.5 & 0.5 \\
$\mathrm{R}_{\mathrm{t}} / \mathrm{k} \Omega \mathrm{cm}^{2}$ & 4500 & 1150 & 220 & 3.50 & 2.50 \\
$\mathrm{R}_{\mathrm{W}} / \mathrm{k} \Omega \mathrm{cm}^{2}$ & - & - & - & 4.5 & 1.51 \\
$\delta^{2} / \mathrm{D} / \mathrm{s}$ & - & - & - & 270 & 193 \\
$\mathrm{P}$ & - & - & - & 0.5 & 0.5 \\
$\mathrm{Y}_{\mathrm{dl}} / \mu \Omega^{-1} \mathrm{~cm}^{-2} \mathrm{~s}^{\mathrm{ndl}}$ & 266 & 297 & 370 & 1960 & 1800 \\
$\mathrm{n}_{\mathrm{dl}}$ & 0.89 & 0.885 & 0.82 & 0.63 & 0.65 \\
\hline
\end{tabular}

t6.1

t6.2 t6.3 t6.4 t6.5 $\mathrm{t} 6.6$ t6.7 $\mathrm{t} 6.8$ t6.9 t6.10 t6.11 t6.12 t6.13 t6.14 
t7.1 Table 7

t7.2 Fitting parameters of EIS spectra and related $\mathrm{E}_{\mathrm{cor}}$ values, obtained in REF mortar.

\begin{tabular}{lccccl}
\hline Time $/$ days & 2 & 9 & 22 & 50 & 78 \\
\hline $\mathrm{E}_{\mathrm{cor}} / \mathrm{V}_{\mathrm{SCE}}$ & -0.098 & -0.11 & -0.082 & -0.382 & -0.181 \\
$\mathrm{R}_{\mathrm{s}}+\mathrm{m} / \Omega \mathrm{cm}^{2}$ & 238 & 328 & 416 & 525 & 600 \\
$\mathrm{R}_{\mathrm{f}} / \Omega \mathrm{cm}^{2}$ & 57 & 57 & 60 & 80 & 100 \\
$\mathrm{Y}_{\mathrm{f}} / \mu \Omega^{-1} \mathrm{~cm}^{-2} \mathrm{~s}^{\mathrm{nf}}$ & 200 & 200 & 200 & 200 & 200 \\
$\mathrm{n}_{\mathrm{f}}$ & 0.9 & 0.9 & 0.85 & 0.64 & 0.56 \\
$\mathrm{R}_{\mathrm{t}} / \mathrm{k} \Omega \mathrm{cm}^{2}$ & 1200 & 1500 & 2500 & 60 & 600 \\
$\mathrm{Y}_{\mathrm{dl}} / \mu \Omega^{-1} \mathrm{~cm}^{-2} \mathrm{~s}^{\text {ndl }}$ & 258 & 243 & 235 & 381 & 262 \\
$\mathrm{n}_{\mathrm{dl}}$ & 0.89 & 0.88 & 0.87 & 0.76 & 0.81 \\
\hline
\end{tabular}

(in the range $-0.5 /-0.6 \mathrm{~V}_{\mathrm{SCE}}$ ) and much higher $\mathrm{i}_{\mathrm{COr}}$ values (about 3$4 \mu \mathrm{A} / \mathrm{cm}^{2}$ ). Under these conditions, high pseudo-passive currents (higher than $10^{-5} \mathrm{~A} / \mathrm{cm}^{2}$ ) were recorded, slowly increasing from $\mathrm{E}_{\mathrm{cor}}$ up to the potential of oxygen evolution, without discontinuity. This curve suggests a degradation of surface film protectiveness which permits significant corrosion at $\mathrm{E}_{\mathrm{cor}}$.

The conditions detected in REF after the same exposure time (43 days) are quite different. In fact, the curves show $\mathrm{E}_{\text {cor }}$ and $\mathrm{i}_{\text {cor }}$ values close to those measured after 8 days (Fig. 10b), suggesting the permanence of passive conditions at $\mathrm{E}_{\mathrm{cor}}$. However, an abrupt current increase was recorded at about $+0.135 \mathrm{~V}_{\mathrm{SCE}}$, due to pitting attack [11]. This means that the surface film has a smaller resistance towards anodic polarization, owing to chloride accumulation (Fig. 4). After 100 days of exposure, a stronger corrosion attack affected the rebars already at $\mathrm{E}_{\text {cor }}\left(\mathrm{i}_{\text {cor }}\right.$ of about $2 \mu \mathrm{A} / \mathrm{cm}^{2}$ ) and rebars were under pseudo-passive conditions. Anyway, $\mathrm{i}_{\text {cor }}$ remained smaller than those obtained in geopolymers after 43 days.

\subsection{Corrosion product analysis}

At the end of the w/d cycles, rebars not used for polarization curve recording were extracted from the mortars to visualize the extent of the corrosion attack and investigate the nature of the corrosion products. In agreement with the suggestions of electrochemical tests, a more widespread corrosion attack was found in FA mortars in comparison to REF, as shown in Fig. 11.

Table 8 reports the results of Raman analysis of corrosion products formed on the steel surface at the end of the $\mathrm{w} / \mathrm{d}$ cycles. A range of diverse amorphous and crystalline oxide structures was found, but abundance of Akaganeite $(\beta-\mathrm{FeO}(\mathrm{OH}, \mathrm{Cl}))$ was detected only in geopolymers with the characteristic cotton balls and rosette shapes [43]. In REF, the most abundant crystalline compound was lepidocrocite $(\gamma-\mathrm{FeO}(\mathrm{OH}))$, while maghemite $\left(\gamma-\mathrm{Fe}_{2} \mathrm{O}_{3}\right)$ and goethite $(\alpha-\mathrm{FeO}(\mathrm{OH})$ were found in traces. Those results are in agreement with the severe corrosion attack detected in geopolymers by the electrochemical tests. In particular, the presence of agakaneite confirms the chloride incorporation in the 586 oxide structure, with the formation of a very scarcely protective surface 587 film [44]. Similar results were also found in [10].

\section{Discussion of the results}

589

In this research, the adoption of decreasing $\mathrm{Na}_{2} \mathrm{O} / \mathrm{SiO}_{2}$ ratios in the 590 activating solution produced geopolymers with more compact micro- 591 structures and higher compressive strength values and elastic moduli 592 (Table 1).G_1 showed the best mechanical properties and, consistently, 593 the highest stability and the lowest apparent diffusion coefficient for 594 chlorides among geopolymers (Tables 1 and 2), even if it remained 595 less performant than REF.

596

In particular, a higher scale porosity was detected in geopolymers, 597 which can be ascribed to the different nature of the gels formed during 598 hardening in these mortar types, in comparison to REF. In fact, whereas 599 $\mathrm{C}-\mathrm{S}-\mathrm{H}$ is the main product usually formed in the latter mortar type, 600 binding phases formed by alkali activation of FA are generally constitut- 601 ed by gels such as $\mathrm{C}-\mathrm{A}-\mathrm{S}-\mathrm{H}, \mathrm{N}-\mathrm{A}-\mathrm{S}-\mathrm{H}$ and $\mathrm{C}-\mathrm{S}-\mathrm{H}$, depending on the 602 precursor chemical composition [20,45,46]. The pores associated with 603 $\mathrm{C}-\mathrm{A}-\mathrm{S}-\mathrm{H}$ and $\mathrm{N}-\mathrm{A}-\mathrm{S}-\mathrm{H}$ gel are larger, mainly due to FA grain dissolu- 604 tion after alkali activation, even if they are often accessed via narrow 605 constrictions caused by ink-bottle pores $[47,48]$. It is well known that 606 the mortar porosity is the pathway through which aggressive species, 607 such as oxygen, chlorides and carbon dioxide, penetrate and induce 608 variations in pore electrolyte composition and corrosion attack on the 609 reinforcing bars.

In REF, after 77 days chloride concentrations of $0.75 \%$ vs binder 611 were measured, that are in the range of those reputed critical for cor- 612 rosion onset in non-carbonated mortars (Fig. 4, [33]). These high 613 chloride concentrations are mainly bound to the mortar gels as low 614 solubility calcium-containing compounds (e.g., Friedel salts, calcium 615 chloride), which represent a reservoir of aggressive chloride ions. 616 Consequently, after 95 days 50\% of the rebars in REF suffered active 617 corrosion (Fig. 7).

In FA mortars, corrosion affected 50\% of the rebars after only 20 days 619 (Fig. 7), in spite of their much lower measured chloride content (Fig. 4). 620 The limited total chloride concentrations are due to the formation of 621 highly soluble alkali metal salts, so that external chlorides can easily 622 penetrate but can also be easily leached out during w/d cycles. However, 623 under these conditions, a relatively high fraction of free aggressive chlo- 624 rides is likely present and available to stimulate the rebar corrosion at- 625 tack. In addition, a fast carbonation was found to affect geopolymers, 626 which is also capable to impair rebar passivity (Fig. 3 and Table 3). 627 The consequent $\mathrm{pH}$ drop in the pore electrolyte causes a decrease in 628 the critical chloride concentration, so that lower chloride concentrations 629 are needed to start corrosion. Geopolymer carbonation was found to 630

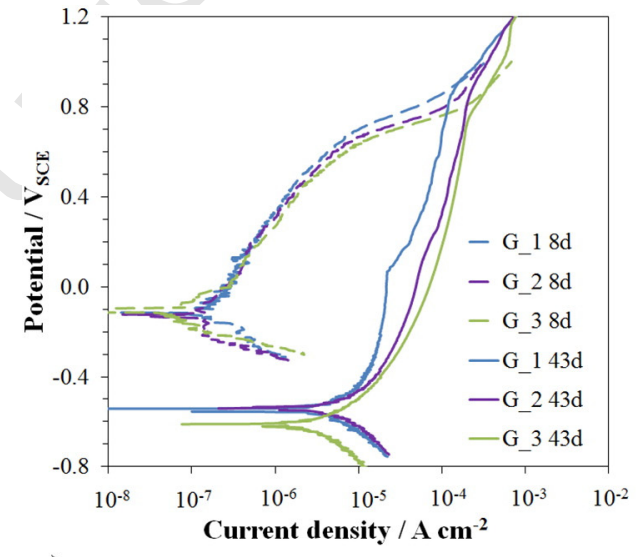

a)

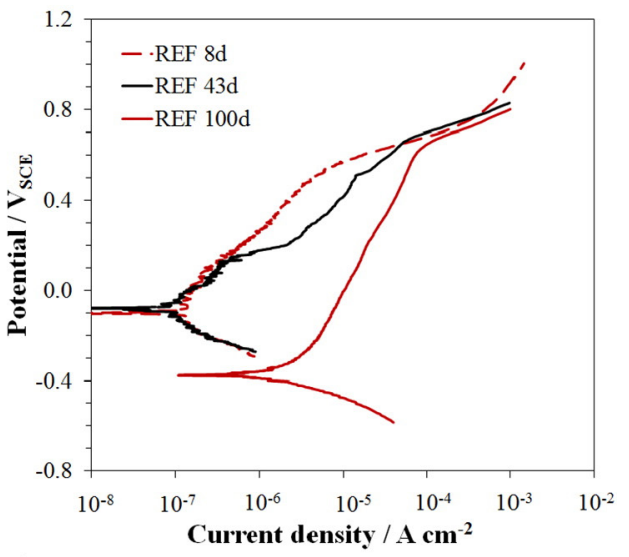

b)

Fig. 10. Polarization curves recorded in the different mortars during the wet step of $\mathrm{w} / \mathrm{d}$ cycles in $0.1 \mathrm{M} \mathrm{NaCl}$ solution. 


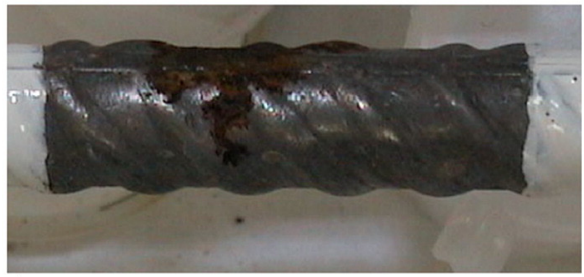

a)

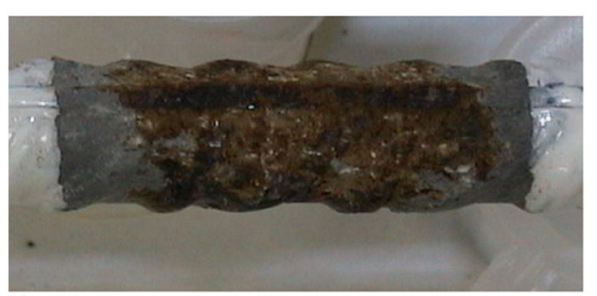

c)

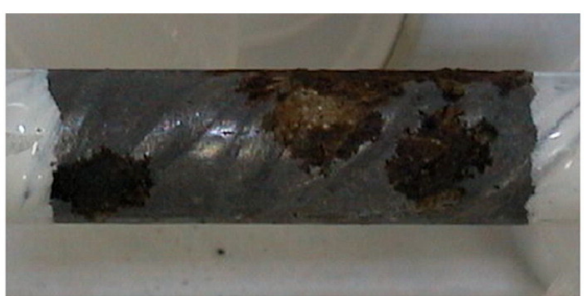

b)

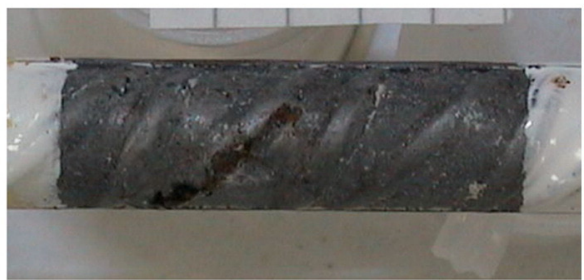

d)

Fig. 11. Extent of corrosion attack on steel bars extracted from samples at the end of electrochemical tests: a) G_1; b) G_2; c) G_3; d) REF.

depend on the $\mathrm{Na}_{2} \mathrm{O} / \mathrm{SiO}_{2}$ ratio in the activating solution, so that $\mathrm{G}_{-} 1$ was the most affected geopolymer, while G_3 was the most resistant to pH variation (Fig. 3). However, the quite porous G_3 microstructure had an overwhelming influence in corrosion stimulation.

The EIS spectra analysis gave results in good agreement with these observations. They clearly evidence that at each exposure time, the mortar compactness (and $R_{s}+m$ values) was highest in REF. The $h f$ loop, describing the dielectric properties of the interfacial mortar region in contact with the rebars, showed $R_{f}$ values depending on both the mortar porosity and the abundance of corrosion products inside the mortar pores. Therefore, the densest REF mortar reached intermediate $R_{f}$ values, because of a limited accumulation of corrosion products in the mortar region close to the rebar surface.

At frequencies lower than $10^{2}-10 \mathrm{~Hz}$, the spectra described the corrosion processes affecting the embedded rebars. In REF, the spectra always showed the persistence of a single If arc, with relatively high $R_{t}$ values, indicative of the persistence of passivity or pseudopassivity on the rebars. In geopolymers, severe corrosion attack developed with time, as indicated by the appearance of a second If capacitive arc, suggesting a mixed charge transfer/diffusion control on the corrosion rate.

\section{Conclusions}

During this research, the corrosion behaviour of rebars embedded in RT-cured geopolymer mortars based on class F FA was assessed during $\mathrm{w} / \mathrm{d}$ exposure to $0.1 \mathrm{M} \mathrm{NaCl}$ solution and it was compared to that shown by rebars in a traditional cement-based mortar under the same aggressive conditions. The differences detected were interpreted in the light of chemical, physical and microstructural differences found in the two systems.

In particular, the results achieved suggested that:

- in geopolymers, a low $\mathrm{Na}_{2} \mathrm{O} / \mathrm{SiO}_{2}$ ratio in the activating solution permitted to achieve the densest microstructure and the best physical- mechanical properties. However, geopolymer performances were 663 inferior to those of REF; 664 - under w/d exposure conditions, all geopolymers suffered a quick 665 mortar carbonation, which was reputed responsible of a fast rebar 666 depassivation, in spite of a low total chloride concentration accumu- 667 lated around the rebars. Instead, REF was more protective as it did 668 not suffer any carbonation.

- fitting of EIS spectra recorded at intervals gave information in good 670 agreement with $\mathrm{E}_{\mathrm{cor}} / \mathrm{R}_{\mathrm{p}}$ measurements and permitted to monitor 671 the evolution of the dielectric properties of interfacial mortar films 672 and electrochemical and mass transport processes affecting passive 673 and corroding rebars.

\section{Acknowledgements}

The authors wish to thank Dr. F. Lolli for her useful assistance in mi- 677 crostructural and mechanical characterizations, Dr. M. Abbottoni for his 678 valuable assistance in performing part of the electrochemical measure- 679 ments and Dr. R. Gaiba for his precious analytical support.

\section{References}

[1] M.S. Imbabi, C. Carrigan, S. McKenna, Trends and developments in green cement 682 and concrete technology, Int. J. Sust. Built Env. 1 (2012) 194-216. 683

[2] J.L. Provis, Geopolymers and other alkali-activated material: why, how and what? 684 Mater. Struct. 47 (2014) 11-25. 685

[3] P. Duxson, J.L. Provis, G.C. Lukey, S.W. Mallicoat, W.M. Kriven, J.S.J. van Deventer, Un- 686 derstanding the relationship between geopolymer composition, microstructure and 687 mechanical properties, Colloids Surf. A Physicochem. Eng. Asp. 269 (2005) 47-58. 688

[4] J.L. Provis, A. Palomo, C. Shi, Advances in understanding alkali-activated materials, 689 Cem. Concr. Res. 78 (2015) 110-125. 690

[5] F. Pacheco-Torgal, Z. Abdollahnejad, A.F. Caomoes, M. Jamshidi, Y. Ding, Durability of 691 alkali-activated binders: a clear advantage over Portland cement or an unproven 692 issue? Constr. Build. Mater. 30 (2012) 400-405. 693

[6] B. Singh, G. Ishwarya, M. Gupta, S.K. Bhattacharyya, Geopolymer concrete: a review 694 of some recent developments, Constr. Build. Mater. 85 (2015) 78-90.

Table 8

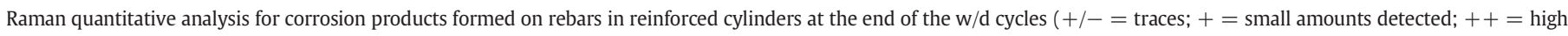
amounts detected).

\begin{tabular}{|c|c|c|c|c|c|}
\hline Sample & Lepidocrocite & Maghemite & Akaganeite & Goethite & $\delta-\mathrm{FeOOH}$ \\
\hline G_1 & $+1-$ & & ++ & & $+1-$ \\
\hline G_2 & & $+/-$ (amorphous) & + (amorphous) & $+/-$ (amorphous) & \\
\hline G_3 & & + (amorphous) & ++ & & \\
\hline REF & + & $+1-$ & & $+1-$ & \\
\hline
\end{tabular}


[7] M.M. Hossain, M.R. Karim, M.K. Hossain, M.N. Islam, M.F.M. Zain, Durability of mortar and concrete containing alkali-activated binder with pozzolans: a review, Constr. Build. Mater. 93 (2015) 95-109.

[8] A. Neville, Chloride attack of reinforced concrete: an overview, Mater. Struct. 28 (1995) 63-70.

[9] M. Criado, S. Martínez-Ramirez, S. Fajardo, P.P. Gómez, J.M. Bastidas, Corrosion rate and corrosion product characterisation using Raman spectroscopy for steel embedded in chloride polluted fly ash mortar, Mater. Corros. 64 (5) (2013) 372-380.

[10] C. Monticelli, M.E. Natali, A. Balbo, C. Chiavari, F. Zanotto, S. Manzi, M.C. Bignozzi, Corrosion behavior of steel in alkali-activated fly ash mortars in the light of their microstructural, mechanical and chemical characterization, Cem. Concr. Res. 80 (2016) 60-68.

[11] C. Monticelli, M. Criado, S. Fajardo, J.M. Bastidas, M. Abbottoni, A. Balbo, Corrosion behavior of a low Ni austenitic stainless steel in carbonated chloride-polluted alkali-activated fly ash mortars, Cem. Concr. Res. 55 (2014) 49-58.

[12] F.U.A. Shaikh, Effects of alkali solutions on corrosion durability of geopolymer concrete, Adv. Concr. Constr. 2 (2) (2014) 109-123.

[13] D.M. Bastidas, A. Fernández-Jiménez, A. Palomo, J.A. González, A study on the passive state stability of steel embedded in activated fly ash mortars, Corros. Sci. 50 (2008) 1058-1065.

[14] J.L. Thompson, B.E. Scheetz, M.R. Schock, D.A. Lytle, P.J. Delaney, Sodium silicate corrosion inhibitors: issues of effectiveness and mechanisms, Proc. Water Quality Technology Conference, November 9-12, 1997, Denver, CO.

[15] J.T. Gourley, G.B. Johnson, Developments in geopolymer precast concrete in geopolymer, green chemistry and sustainable development solutions, in: J. Davidovits (Ed.), Proc. World Congress Geopolymer 2005 2005, pp. 139-143.

[16] J.M. Miranda, A. Fernández-Jiménez, J.A. González, A. Palomo, Corrosion resistance in activated fly ash mortars, Cem. Concr. Res. 35 (2005) 1210-1217.

[17] J.S.J. van Deventer, J.L. Provis, P. Duxson, Technical and commercial progress in the adoption of geopolymer cement, Miner. Eng. 29 (2012) 89-104.

18] J. Temuujin, R.P. Williams, A. van Riessen, Effect of mechanical activation of fly ash on the properties of geopolymer cured at ambient temperature, J. Mater. Process. Technol. 209 (2009) 5276-5280.

[19] N.K. Lee, H.K. Lee, Setting and mechanical properties of alkaliactivated fly ash/slag concrete manufactured at room temperature, Constr. Build. Mater. 47 (2013) 1201-1209.

[20] M.C. Bignozzi, S. Manzi, M.E. Natali, W.D.A. Richard, A. van Riessen, Room temperature alkali activation of fly-ash: the effect of $\mathrm{Na}_{2} \mathrm{O} / \mathrm{SiO}_{2}$ ratio, Constr. Build. Mater. 69 (2014) 262-270.

[21] P. Nath, P.K. Saker, Use OPC to improve setting and early stregth properties of low calcium fly ash geopolymer concrete cured at room temperature, Cem. Concr. Compos. 55 (2015) 205-214.

[22] EN 196-1, Methods of Testing Cement - Part 1: Determination of Strength, 2005.

23] EN 12617-4, Products and Systems for the Protection and Repair of Concrete Structures - Test Methods - Determination of Shrinkage and Expansion, 2003.

[24] DIN 66133, Determination of Pore Volume Distribution and Specific Surface Area of Solids by Mercury Intrusion, 1993.

[25] ASTM, C1556. Standard Test Method for Determinig the Apparent Chloride Diffusion Coefficient of Cementitious Mixtures by Bulk Diffusion, 2003.

[26] ASTM C1152/C1152M, Standard Test Method for Acid-soluble Chloride in Mortar and Concrete, 2004.

27] ASTM C114, Standard Test Methods for Chemical Analysis of Hydraulic Cement, 2011.

[28] V. Räsänen, V. Penttala, The pH measurement of concrete and smoothing mortar using a concrete powder suspension, Cem. Concr. Res. 34 (2004) 813-820.
[29] M. Serdar, L. Valek Žulj, D. Bjegović, Long-term corrosion behaviour of stainless 751 reinforcing steel in mortar exposed to chloride environment, Corros. Sci. 69752 (2013) 149-157.

[30] T. Xie, T. Ozbakkaloglu, Behavior of low-calcium fly and bottom ash-based 754 geopolymer concrete cured at ambient temperature, Ceram. Int. 41 (2015) 755 5945-5958.

[31] F. Collins, J.G. Sanjayan, Effect of pore size distribution on drying shrinkage of alkali 757 activated slag concrete, Cem. Concr. Res. 30 (2000) 1401-1406. 758

[32] M. Fernandez Bertos, S.J.R. Simons, C.D. Hills, P.J. Carey, A review of accelerated car- 759 bonation technology in the treatment of cement-based materials and sequestration 760 of $\mathrm{CO}_{2}$, J. Hazard. Mater. B112 (2004) 193-205. 761

[33] U. Angst, B. Elsener, C.K. Larsen, G.C. Luckey, Ø. Vennesland, Critical chloride content 762 in reinforced concrete - a review, Cem. Concr. Res. 39 (2009) 1122-1138. 763

[34] M. Ismail, M. Ohtsu, Corrosion rate of ordinary and high-performance concrete 764 subjected to chloride attack by AC impedance spectroscopy, Constr. Build. Mater. 765 20 (2006) 458-469.

[35] M.F. Montemor, M.P. Simoes, M.M. Salta, M.G.S. Ferreira, The assessment of the elec- 767 trochemical behaviour of fly ash-containing concrete by impedance spectroscopy, 768 Corros. Sci. 35 (1993) 1571-1578.

[36] M. Keddam, H. Takenouti, X.R. Nóvoa, C. Andrade, C. Alonso, Impedance measure- 770 ments on cement paste, Cem. Concr. Res. 27 (1997) 1191-1201. 771

[37] V. Feliu, J.A. Gonzalez, C. Andrade, S. Feliu, Equivalent circuit for modelling the steel- 772 concrete interface. I. Experimental evidence and theoretical predictions, Corros. Sci. 773 40 (1998) 975-993.

[38] P. Gu, S. Elliot, J.J. Beaudoin, B. Arsenault, Corrosion resistance of stainless steel in 775 chloride contaminated concrete, Cem. Concr. Res. 26 (1996) 1151-1156. 776

[39] L. Yohai, M.B. Valcarce, M. Vázquez, Testing phosphate ions as corrosion inhibitors 777 for construction steel in mortars, Electrochim. Acta 202 (2016) 316-324. 778

[40] K.K. Sagoe-Crentsil, F.P. Glasser, J.T.S. Irvine, Electrochemical characteristics of 779 reinforced concrete corrosion as determined by impedance spectroscopy, Br. Corros. 780 J. 27 (1992) 113-118.

[41] G. Trabanelli, C. Monticelli, V. Grassi, A. Frignani, Electrochemical study on inhibitors 782 of rebar corrosion in carbonated concrete, Cem. Concr. Res. 35 (2005) 1804-1813. 783

[42] E. Volpi, A. Olietti, M. Stefanoni, S.P. Trasatti, Electrochemical characterization of 784 mild steel in alkaline solutions simulating concrete environment, J. Electroanal. 785 Chem. 736 (2015) 38-46.

[43] J.D. Moreno, M. Bonilla, J.M. Adam, M.V. Borrachero, L. Soriano, Determining corro- 787 sion levels in the reinforcement rebars of buildings in costal areas. A case study in 788 the Mediterranean coastline, Constr. Build. Mater. 100 (2015) 11-21. 789

[44] P. Refait, J.M.R. Genin, The mechanisms of oxidation of ferrous hydroxychloride $\beta-790$ $\mathrm{Fe}_{2}(\mathrm{OH})_{3} \mathrm{Cl}$ in aqueous solution: the formation of akaganeite vs goethite, Corros. 791 Sci. 33 (1993) 539-553.

[45] I. Ismail, S.A. Bernal, J.L. Provis, R. San Nicolas, D.G. Brice, A.R. Kilcullen, et al 793 Influence of fly ash on the water and chloride permeability of alkali activated slag 794 mortars and concrete, Constr. Build. Mater. 48 (2013) 1187-1201. 795

[46] I. Garcia-Lodeiro, A. Palomo, A. Fernández-Jiménez, D.E. Macphee, Compatibility 796 studies between $\mathrm{N}-\mathrm{A}-\mathrm{S}-\mathrm{H}$ and $\mathrm{C}-\mathrm{A}-\mathrm{S}-\mathrm{H}$ gels. Study in the ternary diagram 797 $\mathrm{Na}_{2} \mathrm{O}-\mathrm{CaO}-\mathrm{Al}_{2} \mathrm{O}_{3}-\mathrm{SiO}_{2}-\mathrm{H}_{2} \mathrm{O}$, Cem. Concr. Res. 41 (2011) 923-931. 798

[47] Y. Ma, J. Hu, G. Ye, The pore structure and permeability of alkali activated fly ash, 799 Fuel 104 (2013) 771-780.

[48] R.R. Lloyd, J.L. Provis, K.J. Smeaton, J.S.J. van Deventer, Spatial distribution of pores in fly ash-based inorganic polymer gels visualized by Wood's metal intrusion, Microporous Mesoporous Mater. 126 (2009) 32-39. 